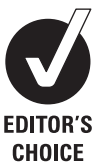

CHOICE

\title{
Early postnatal hypotension and developmental delay at 24 months of age among extremely low gestational age newborns
}

\author{
J Wells Logan, ${ }^{1}$ T Michael O'Shea, ${ }^{2}$ Elizabeth N Allred, ${ }^{3-5}$ Matthew M Laughon, ${ }^{6}$ \\ Carl L Bose, ${ }^{6}$ Olaf Dammann, ${ }^{7}$ Daniel G Batton, ${ }^{8}$ Stephen C Engelke, ${ }^{9}$ Alan Leviton ${ }^{4,5}$; \\ for the ELGAN Study Investigators
}

\begin{abstract}
See Editorial, p F316
${ }^{1}$ New Hanover Regional

Medical Center, Wilmington,

North Carolina, USA

${ }^{2}$ Wake Forest University

School of Medicine.

Winston-Salem, North

Carolina, USA

${ }^{3}$ Harvard School of

Public Health, Boston,

Massachusetts, USA

${ }^{4}$ Harvard Medical School,

Boston, Massachusetts, USA

${ }^{5}$ Children's Hospital Boston,

Boston, Massachusetts, USA

${ }^{6}$ The University of North

Carolina at Chapel Hill, Chapel

Hill, North Carolina, USA

${ }^{7}$ Floating Hospital, Tufts

Medical Center, Boston

Massachusetts, USA

${ }^{8}$ Southern Illinois University

School of Medicine

Springfield, Illinois, USA

${ }^{9}$ East Carolina University,

Brody School of Medicine,

Greenville, North Carolina,

USA
\end{abstract}

\section{Correspondence to}

Dr J W Logan, Division of

Neonatal-Perinatal Medicine,

Betty H Cameron Women's

and Children's Hospital,

2131 South 17th Street,

Wilmington, NC 28402, USA;

wells.logan@ccneo.net

Accepted 10 October 2010

Published Online First

7 December 2010

\begin{abstract}
ABSTARCT
Objectives To evaluate in extremely low gestational age newborns, relationships between indicators of hypotension during the first 24 postnatal hours and developmental delay at 24 months of age.

Methods The 945 infants in this prospective study were born at $<28$ weeks, were assessed for three indicators of hypotension in the first 24 postnatal hours, and were evaluated with the Bayley Mental Development Index (MDI) and Psychomotor Development Index (PDI) at 24 months corrected age. Indicators of hypotension included: (1) mean arterial pressure in the lowest quartile for gestational age;

(2) treatment with a vasopressor; and (3) blood pressure lability, defined as the upper quartile for the difference between the lowest and highest mean arterial pressure. Logistic regression was used to evaluate relationships between hypotension and developmental outcomes, adjusting for potential confounders.
\end{abstract}

Results $78 \%$ of infants in this cohort received volume expansion or vasopressor; all who received a vasopressor were treated with volume expansion. $26 \%$ had an MDI $<70$ and $32 \%$ had a PDI $<70$. Low MDI and PDI were associated with low gestational age, which in turn, was associated with receipt of vasopressor treatment. Blood pressure in the lowest quartile for gestational age was associated with vasopressor treatment and labile blood pressure. After adjusting for potential confounders, none of the indicators of hypotension were associated with $\mathrm{MDI}<70$ or $\mathrm{PDI}<70$.

Conclusions In this large cohort of extremely low gestational age newborns, we found little evidence that early postnatal hypotension indicators are associated with developmental delay at 24 months corrected gestational age.

\section{INTRODUCTION}

The term 'cerebral blood flow autoregulation' is used to indicate that compensatory mechanisms can assure normal cerebral blood flow even when systemic blood pressure is reduced. Some preterm infants have impaired cerebral autoregulation, while others may have a blood pressure below the autoregulatory plateau. ${ }^{12}$ However, clinical identification of these physiological impairments remains elusive. Nevertheless, clinicians frequently choose to treat hypotension in the preterm newborn in order to avoid brain damage that might result from impaired cerebral perfusion.

Conflicting results have been obtained in small observational studies of the association of low

\section{What is already known on this topic}

The available literature contains conflicting results regarding the association of hypotension and brain damage in ELGANs.

\section{What this study adds}

- We found little support for the concept that early postnatal hypotension indicators are associated with developmental delay, or that vasopressor therapy decreases that risk.

- Inferences from this study are most pertinent to populations in which volume expansion is used frequently, as the majority of infants in this cohort received volume expansion.

arterial blood pressure (variably defined) and brain damage. In some studies, ${ }^{3-9}$ but not in others, ${ }^{10-19}$ low blood pressure has been associated with a higher risk of intraventricular haemorrhage or white matter damage identified by cranial ultrasound. The few studies reporting an association between hypotension and developmental delay were small and do not appear to have adequately controlled for potential confounders. ${ }^{820-22}$

The Extremely Low Gestational Age Newborn (ELGAN) Study provided the opportunity to evaluate the relationship between hypotension indicators in the first 24 postnatal hours and developmental delay at 24 months, in a large multi-centre cohort of infants born prior to 28 weeks gestation.

\section{METHODS}

The ELGAN Study was designed to identify characteristics and exposures that increase the risk of structural and functional neurological disorders in ELGANs. During the years 2002-2004, women whose babies were delivered before 28 weeks gestation were asked to enrol in the study. The project was overseen by the National Institutes of Health, the institutional review boards of the 14 participating institutions, and an external Performance Monitoring and Safety Board (members appointed by the National Institutes of Neurologic Disorders and Stroke) at Children's Hospital Boston. All variables and outcomes were defined a priori, and research personnel were trained prior to the start 
of the study. This study is a post-hoc epidemiological analysis of prospectively acquired data from the original sample of 1506 infants born in 14 centres in 11 cities in the USA.

\section{Study participants}

Mothers of eligible infants were approached for consent either upon antenatal admission or shortly after delivery, depending on clinical circumstance and institutional preference. In all, 1249 mothers consented to participate, and their 1506 infants (1002 singletons, 504 twins or higher order) were enrolled. There were 260 mothers who were missed or did not consent. All infants were born at Level III neonatal intensive care units, in either urban or suburban academic institutions.

\section{Demographic, pregnancy and delivery variables}

The clinical circumstances that led to each maternal admission and ultimately to each preterm delivery were operationally defined using data from a structured maternal interview and abstracted from the medical record. ${ }^{23}$ Shortly after the mother's discharge, the research nurse reviewed the maternal chart using a second structured data collection form. The medical record was relied on for all events and characteristics following admission. Variables evaluated as potential confounders included, but were not limited to, pregnancy complications and exposures (ie, antenatal steroids and magnesium), placental characteristics (ie, chorioamnionitis, funisitis and thrombosis) and neonatal characteristics ascertained at birth (ie, gestational age, race, gender and anthropomorphic measurements).

\section{Newborn variables}

The gestational age estimates were based on a hierarchy of the quality of available information. Most desirable were estimates based on the dates of embryo retrieval, intrauterine insemination or fetal ultrasound before the 14 th week (62\%). When these were not available, reliance was placed sequentially on a fetal ultrasound at 14 or more weeks (29\%), dates of the last menstrual period without fetal ultrasound (7\%) and gestational age recorded in the log of the neonatal intensive care unit (1\%). The birthweight Z-score and head circumference Z-score represent the number of SDs the infant's weight or head circumference is above or below the mean of infants at the same gestational age in a standard data set. ${ }^{24}$

\section{Hypotension indicators}

The frequency of hypotension indicators was higher in the first 24 postnatal hours than on subsequent days. So was the severity of hypotensive episodes. Because brain damage that can be attributed to severe hypotension was most likely to have occurred then, we studied the lowest mean arterial pressure (MAP) measured during the first postnatal day. Because no single definition of hypotension is widely accepted, ${ }^{19} 25$ we examined three indicators of hypotension in the first 24 postnatal hours, including: (1) MAP in the lowest quartile for gestational age (23-24, 25-26 and 27 weeks); (2) treatment for hypotension using a vasopressor (dopamine, dobutamine, epinephrine); and (3) blood pressure lability, defined as the upper quartile for the quantity (highest MAP-lowest MAP).

Data forms were developed prior to the start of the study, and multiple training sessions were held to train research personnel in standardised approaches to data collection from the hospital chart. The lowest, highest and mode blood pressure measurements for each day were abstracted from the medical record. We did not collect information about the method used for measuring blood pressure (oscillometry vs intra-arterial catheter). MAP in the lowest quartile represents the lowest quartile blood pressures for a broad sample of ELGANs. Vasopressor use served as a 'functional' definition of hypotension; regardless of how the clinician arrived at the decision to treat, he/she deemed the infant hypotensive enough to require treatment. Blood pressure lability was chosen because it has been associated with intraventricular haemorrhage. ${ }^{17}$

Because $75 \%$ of the infants in this study received volume expansion in the first $24 \mathrm{~h}$, receipt of volume expansion was not included as a variable in analyses.

\section{4-Month developmental assessment}

A developmental assessment was performed by certified examiners at 24 months corrected gestational age. Families were invited to bring their child for a developmental assessment, which included the Bayley Scales of Infant Developmentsecond edition (BSID-II). ${ }^{26}$ Only $2 \%$ of examiners indicated at the time of the examination that they had more than a limited amount of information about the child. Before testing, examiners were told the child's age. After completion of testing, examiners were told the gestational age so that the Mental Development Index (MDI) and Psychomotor Development Index (PDI) could be appropriately age-adjusted.

Developmental delay was defined as either an MDI $<70$ or a PDI $<70$. The child was classified as 'not testable' on a scale if her/his impairments prohibited standardised administration, or more than two items were judged to be 'not applicable'. On the basis of their Vineland Adaptive Behavior Scales Composite score, 26 of 33 children considered 'not-testable' were assigned an MDI of $<70(\mathrm{~N}=23)$ or $\geq 70(\mathrm{~N}=3) .{ }^{27}$ On the basis of the motor scale (\#4) of the Vineland Adaptive Behavior Scales, 32 of 38 considered 'not testable' were assigned a PDI of $<70(\mathrm{~N}=27)$ or $\geq 70(\mathrm{~N}=5)$.

\section{Data analysis}

We evaluated the null hypothesis that children with an indicator of hypotension during the first 24 postnatal hours were no more likely than their peers to have developmental delay at 24 months.

In order to detect potential confounders, we compared the distribution of other characteristics and exposures among children who had each indicator of hypotension to the distribution among children who did not. We then compared the distribution of these characteristics and exposures among children who did and did not have an MDI $<70$ or a PDI $<70$. To be identified as a potential confounder, characteristics and exposures of the pregnancy, delivery and postnatal period had to be associated with both the exposure (hypotension indicator) and the outcome (low Bayley score) with a $\mathrm{p}$ value $\leq 0.25 .^{28}$

Outcome measures were modelled as dichotomies (eg, $\mathrm{MDI}<70$ and $\mathrm{MDI} \geq 70$ ). We fit six logistic regression models, one for each of two outcomes with each of the three hypotension indicators. Each model was adjusted for identified potential confounders and included a hospital cluster term to account for the possibility that infants born at a particular hospital are more like each other than infants born at other hospitals. ${ }^{29}$

Here, we present data adjusted for gestational age in groups of weeks (ie, 23-24, 25-26 and 27 weeks). Early analyses included an adjustment for illness severity (SNAP-II). ${ }^{30}$ However, because lowest MAP in the first $12 \mathrm{~h}$ is a component 


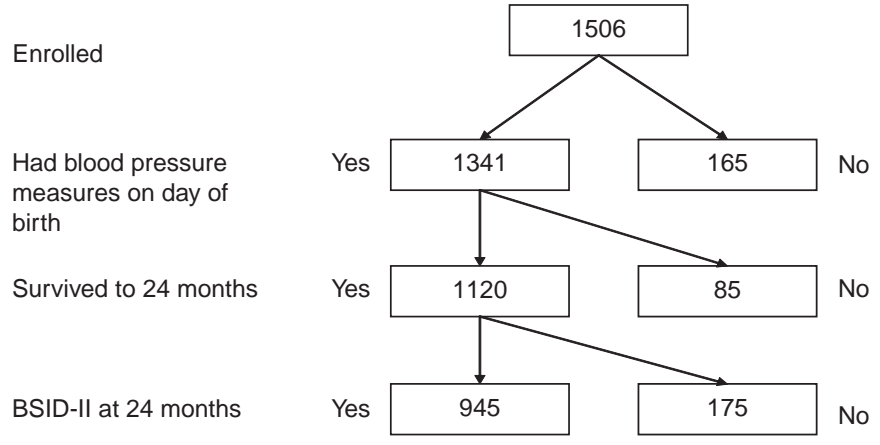

Figure 1 Sample for analyses of hypotension and developmental delay.

of SNAP-II, it was removed from the model. Removal of the adjustment for illness severity resulted in no difference in adjusted ORs (data not shown).

We present, graphically, the ORs and 95\% CIs for MDI $<70$ and PDI $<70$ related to each of the three indicators of hypotension.

\section{RESULTS}

The original ELGAN sample consists of 1506 infants born to 1249 mothers. The sample for this analysis included the 945 infants (from 783 mothers) who were evaluated with the BSID-II at 2 years corrected age and for whom we had our three measures of hypotension (see figure 1). Of the 945 infants who were evaluated at follow-up, 629 were singletons and 316 were multiples.

To evaluate the potential for bias due to surviving infants who were lost to follow-up at 24 months of age, we compared characteristics of infants who returned for follow-up to those who did not (table 1). Mothers who brought their child for a developmental assessment were more educated and more likely to be married. Their babies were born later in gestation, and were more likely to have a hypotension indicator.

In the first 24 postnatal hours, $741 / 945$ (78\%) of infants in this cohort received either volume expansion or vasopressor support. Seventy-five per cent received volume expansion and $26 \%$ received one or more vasopressor. All infants who received a vasopressor were treated with volume expansion. Twentytwo per cent were hypotensive, defined as MAP in the lowest quartile for gestation, and $64 \%$ were hypotensive, defined as MAP (in $\mathrm{mm} \mathrm{Hg}$ ) less than gestational age (in weeks). Due to the high proportion of infants with MAP less than gestational age, any relationship between MAP in the lowest quartile for gestation and other characteristics, exposures and abnormal development, would be statistically stronger than a relationship identified with MAP less than gestational age. We report only the results for hypotension defined as MAP in the lowest quartile for gestation.

\section{Infant characteristics}

Twenty-five per cent of the study cohort had blood pressure in the lowest quartile, whereas $21 \%$ of survivors had a blood pressure this low, indicating an association between blood pressure in the lowest quartile and mortality (table 2, figure 2). Twenty-six per cent of infants were treated with vasopressors and $24 \%$ had labile blood pressure. Twenty-six per cent of infants had an MDI $<70$ and $32 \%$ had a PDI $<70$.

The rate of $\mathrm{MDI}<70$ was higher in males, but males were only minimally more likely to have a hypotension indicator.
Table 1 Comparison of characteristics of mothers and children who were followed to those of mothers and children who were not (column per cents).

\begin{tabular}{|c|c|c|c|}
\hline $\begin{array}{l}\text { Maternal or infant } \\
\text { characteristic }\end{array}$ & & Followed & Not followed \\
\hline \multirow[t]{5}{*}{ Maternal education } & $<12$ & 18 & 24 \\
\hline & 12 (High school) & 26 & 28 \\
\hline & $>12$ to $<16$ & 23 & 28 \\
\hline & College grad & 18 & 14 \\
\hline & $>16$ & 14 & 6 \\
\hline Married & Yes & 56 & 44 \\
\hline Public insurance & Yes & 41 & 50 \\
\hline \multirow[t]{6}{*}{ Delivery complication } & Preterm labour & 43 & 43 \\
\hline & pPROM & 22 & 22 \\
\hline & Pre-eclampsia & 15 & 11 \\
\hline & Abruption & 11 & 10 \\
\hline & Cerv insufficiency & 5 & 7 \\
\hline & Fetal indication & 3 & 6 \\
\hline Sex & Male & 53 & 55 \\
\hline Black race & Yes & 27 & 27 \\
\hline \multirow[t]{3}{*}{ Gestational age (weeks) } & $23-24$ & 20 & 26 \\
\hline & $25-26$ & 47 & 46 \\
\hline & 27 & 33 & 29 \\
\hline \multirow[t]{3}{*}{ Birthweight Z-score ${ }^{\S}$} & $<-2$ & 6 & 3 \\
\hline & $\geq-2,<-1$ & 12 & 11 \\
\hline & $>-1$ & 82 & 86 \\
\hline \multirow[t]{3}{*}{ Head circumference Z-score ${ }^{\S}$} & $<-2$ & 8 & 5 \\
\hline & $\geq-2,<-1$ & 23 & 20 \\
\hline & $>-1$ & 69 & 75 \\
\hline Lowest 1/4ile MAP* & Yes & 22 & 15 \\
\hline Vasopressor $^{\dagger}$ & Yes & 26 & 19 \\
\hline Labile MAP $\ddagger$ & Yes & 24 & 17 \\
\hline Max number of infants & & 945 & 175 \\
\hline
\end{tabular}

*Lowest 1/4ile MAP: lowest mean arterial pressure recorded in the first $24 \mathrm{~h}$, in the lowest quartile for gestational age.

${ }^{\dagger}$ Vasopressor: treatment for hypotension in the first $24 \mathrm{~h}$, using any vasopressor (dopamine, dobutamine, epinephrine).

‡Labile MAP: labile blood pressure, defined as the upper quartile of the difference in the lowest and highest mean arterial pressure. §Yudkin standard. ${ }^{24}$

Lower gestational age was associated with higher risk of vasopressor treatment and labile blood pressure and also with a higher risk of MDI or PDI $<70$.

Infants with a low birthweight Z-score were at higher risk of a blood pressure in the lowest quartile for gestation, labile blood pressure and $\mathrm{MDI}$ or $\mathrm{PDI}<70$. Infants with a low birthweight Z-score and low head circumference Z-score, a correlate of low birthweight Z-score, also had a heightened risk of an MDI or PDI <70 (see footnote for figure 3).

\section{Social, demographic and pregnancy characteristics}

Indicators of social disadvantage, specifically maternal education less than 12 years and public insurance, were associated with a higher rate of MDI <70 but not with any hypotension indicator (see footnote for figure 3) (table 3).

\section{Univariate relationships: hypotension indicators and developmental delay}

While vasopressors were given more frequently to infants with MAP in the lowest quartile for gestation, hypotension and vasopressor therapy were not associated with the risk of low MDI or PDI (table 4). 
Table 2 Infant characteristics, indicators of hypotension and developmental delay (row per cents)

\begin{tabular}{|c|c|c|c|c|c|c|c|}
\hline \multirow{2}{*}{\multicolumn{2}{|c|}{ Characteristics of the infant }} & \multirow{3}{*}{$\begin{array}{l}\text { Lowest 1/4ile MAP* } \\
22\end{array}$} & \multirow{3}{*}{$\begin{array}{c}\text { Vasopressor }^{\dagger} \\
28\end{array}$} & \multirow{3}{*}{$\begin{array}{l}\text { Labile MAP } \\
25\end{array}$} & \multicolumn{2}{|c|}{ BSID $<70$} & \multirow{3}{*}{$\begin{array}{l}\mathbf{N} \\
497\end{array}$} \\
\hline & & & & & \multirow{2}{*}{$\begin{array}{c}\text { MDI } \\
32\end{array}$} & \multirow{2}{*}{$\begin{array}{r}\text { PDI } \\
34\end{array}$} & \\
\hline Sex & Male & & & & & & \\
\hline & Female & 22 & 24 & 23 & 20 & 29 & 448 \\
\hline \multirow[t]{2}{*}{ Black race } & Yes & 27 & 26 & 31 & 40 & 35 & 253 \\
\hline & No & 20 & 26 & 21 & 22 & 30 & 677 \\
\hline \multirow[t]{2}{*}{ Type of gestation } & Singleton & 22 & 23 & 26 & 25 & 30 & 632 \\
\hline & Multiple & 21 & 32 & 20 & 27 & 36 & 313 \\
\hline \multirow[t]{3}{*}{ Gestational age (weeks) } & $23-24$ & 19 & 37 & 28 & 37 & 40 & 190 \\
\hline & $25-26$ & 20 & 24 & 23 & 26 & 31 & 443 \\
\hline & 27 & 26 & 21 & 22 & 21 & 27 & 312 \\
\hline \multirow[t]{4}{*}{ Birthweight (g) } & $\leq 750$ & 21 & 31 & 28 & 35 & 39 & 346 \\
\hline & $751-1000$ & 24 & 25 & 23 & 24 & 28 & 421 \\
\hline & $1001-1250$ & 19 & 17 & 18 & 15 & 25 & 162 \\
\hline & $>1250$ & 13 & 44 & 18 & 19 & 31 & 16 \\
\hline \multirow[t]{3}{*}{ Birthweight Z-score ${ }^{\S}$} & $<-2$ & 26 & 23 & 32 & 38 & 51 & 53 \\
\hline & $\geq-2,<-1$ & 24 & 27 & 29 & 32 & 36 & 117 \\
\hline & $\geq-1$ & 21 & 26 & 22 & 25 & 30 & 775 \\
\hline \multirow{3}{*}{$\begin{array}{l}\text { Birth head circumference } \\
\text { Z-score }\end{array}$} & $<-2$ & 27 & 30 & 26 & 36 & 45 & 73 \\
\hline & $\geq-2,<-1$ & 22 & 23 & 24 & 31 & 31 & 207 \\
\hline & $\geq-1$ & 22 & 26 & 23 & 25 & 30 & 634 \\
\hline \multicolumn{2}{|l|}{ Max number of infants } & 206 & 244 & 225 & 250 & 300 & 945 \\
\hline \multicolumn{2}{|l|}{ Row per cent } & 22 & 26 & 24 & 26 & 32 & \\
\hline
\end{tabular}

*Lowest 1/4ile MAP: lowest mean arterial pressure recorded in the first $24 \mathrm{~h}$, in the lowest quartile for gestational age.

${ }^{\dagger}$ Vasopressor: treatment for hypotension in the first $24 \mathrm{~h}$, using any vasopressor (dopamine, dobutamine, epinephrine).

${ }^{\ddagger}$ Labile MAP: labile blood pressure, defined as the upper quartile of the difference in the lowest and highest mean arterial pressure.

\$Yudkin standard. ${ }^{24}$

BSID, Bayley Scales of Infant Development; MDI, Mental Developmental Index; PDI, Psychomotor Developmental Index.

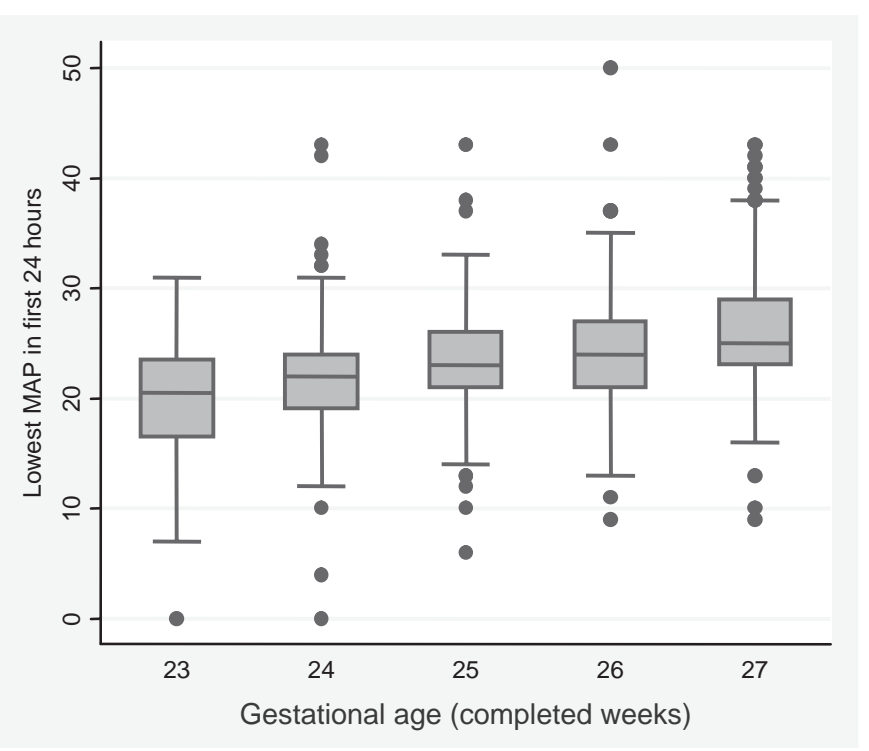

Figure 2 Lowest mean arterial pressure (MAP; $\mathrm{mm} \mathrm{Hg}$ ) in the first $24 \mathrm{~h}$ and gestational age (weeks). The bottom of each dark box marks the upper boundary of the lowest quartile, and measures below this boundary are those that were included in our analyses as a hypotension indicator. Asterisks represent others.

\section{Multivariate relationships: hypotension indicators and developmental delay}

In the unadjusted models for MDI $<70$, use of vasopressors approached, but did not reach, statistical significance with an OR of 1.4 (95\% CI 0.98 to 2.0) (figure 3). After adjusting for confounders, none of the indicators of hypotension studied here were significantly associated with an MDI $<70$ or a PDI
$<70$. Similar results were obtained when infants who were considered 'not-testable' were excluded from analyses.

\section{DISCUSSION}

In this study, $78 \%$ of infants received some treatment (volume expansion or vasopressor therapy) for hypotension. The proportion of infants treated for hypotension varied greatly among the 14 centres, even after adjustment for maternal and neonatal risk factors. ${ }^{25}$ Although we do not know what provoked the majority of clinicians to initiate treatment for hypotension, it is likely that the perception of harm to the central nervous system was a key motivation. In this large cohort of extremely preterm infants, a majority of whom were treated with volume expanders, we found little evidence for an association between early postnatal hypotension indicators and developmental delay.

The correlation of systemic blood pressure with indicators of cerebral and systemic blood flow has been studied using several techniques, including near-infrared spectroscopy (NIRS), 23132 trans-cranial Doppler, ${ }^{33} 34$ superior vena cava blood flow ${ }^{34-36}$ and ventricular output. ${ }^{36-38}$ Of these, NIRS and Doppler are the only techniques capable of providing a direct and continuous measure of cerebral perfusion. This could explain why studies employing the continuous measurement of blood pressure and NIRS seem to favour a correlation between blood pressure and cerebral perfusion, 231323940 while studies employing the intermittent collection of blood pressure and NIRS, ${ }^{41-44}$ and other indicators of upper body blood flow ${ }^{36} 38$ and cerebral perfusion, ${ }^{33} 45$ frequently do not. Nonetheless, blood pressure might not be a sensitive indicator of the putative effect of insufficient cerebral perfusion in the preterm brain, as abnormalities of cerebral blood flow have been associated with cranial 


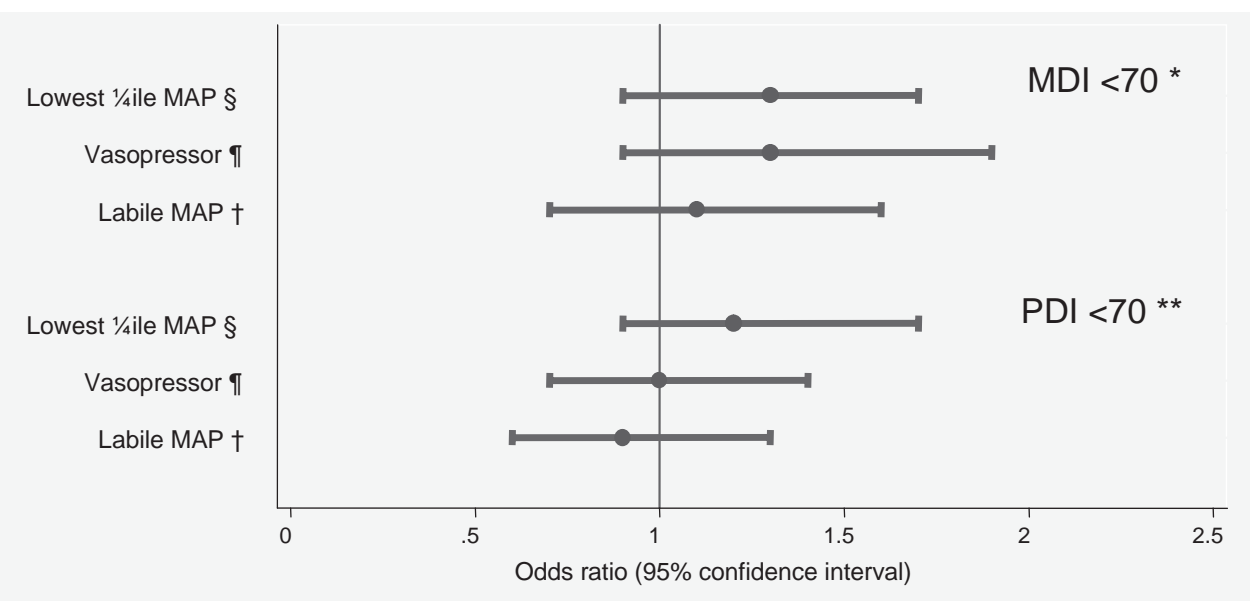

* $\quad$ Adjustedfor bl ack race, public insurance, primagravida, male sex, gestational age 23-24 weeks, birth weight $Z$-score $<-1$, and center

** Adjusted for public insurance, male sex, multiple birth, gestational age 23-24 weeks, birth weight $Z$-score $<-1$, and center

§ Lowest $1 / 4$ ile MAP : lowest MAP recorded in the first 24 hours, in the lowest quartile for gestational age

I Vasopressor: treatment for hypotension in the first 24 hours, using any vasopressor (dopamine, dobutamine, epinephrine)

$\dagger \quad$ Labile MAP: labile blood pressure, defined as the upper quartile of the difference in the lowest and highest MAP

MDI Mental Developmental Index

PDI Psychomotor Developmental Index

Figure 3 ORs (and 95\% Cls) of the risk of $\mathrm{MDI}<70$ and $\mathrm{PDI}<70$ obtained with logistic regression models that incorporate indicators of hypotension during the first 24 postnatal hours and potential confounders.

ultrasound lesions, ${ }^{34} 39$ 46-51 while systemic hypotension has not. ${ }^{10-19}$ Moreover, just as the aetiology of brain damage in preterm newborns is multifactorial, ${ }^{14} 5253$ so are the clinical factors that modify cerebral perfusion. ${ }^{54-56}$

Our finding that early postnatal hypotension is not associated with developmental delay at follow-up agrees with conclusions from one prior study ${ }^{57}$ and contrasts with the conclusions of several others. ${ }^{8} 20-22$ Studies reporting an association between hypotension and developmental delay were small, single-centre studies, decreasing the likelihood that multiple potential confounders could be adequately controlled. ${ }^{820-22}$ Hypotensive infants are frequently treated with vasopressors, yet only two of the studies reporting an association between hypotension and developmental delay adequately controlled for treatment. ${ }^{21} 22$ Further, two of the studies favouring an association between hypotension and developmental delay reported composite developmental outcomes. ${ }^{822}$ Since individual outcomes do not contribute equally to composite measures, the overall effect estimate for a composite measure cannot be assumed to apply equally to each of its individual outcomes. ${ }^{58}$

Our failure to detect an association between early postnatal hypotension indicators and developmental delay has several possible explanations. The first is that early postnatal hypotension is not associated with brain damage in preterm newborns. The second is that if poor cerebral perfusion is associated with brain damage in preterm newborns, then early postnatal hypotension is not a reliable indicator of poor cerebral perfusion. The third is that if poor cerebral perfusion is associated with brain damage in preterm newborns, and hypotension is a reliable indicator of poor cerebral perfusion, then our intermittent and crude collection of blood pressure is not a reliable indicator of hypotension, and by extension, an inadequate indicator of poor cerebral perfusion.
Because none of the potential confounders are in any way negatively associated with low blood pressure or low BSID, we do not consider negative confounding an explanation for our failure to detect an association between early postnatal hypotension and developmental delay. ${ }^{59}$ Our study sample was large enough to detect the confounding influence of treatment (with vasopressors) on outcome, and our results suggest a near-significant association between vasopressor use and developmental delay. A possible explanation for this finding is that use of vasopressors could have adverse effects. An alternative explanation is that the severe physiologic abnormalities that prompted therapy provide information about the risk of brain damage. This would occur if clinicians provided therapy to those infants at highest risk of morbidities, for example, infants born at lower gestational age, ${ }^{60}$ a bias referred to as confounding by indication. ${ }^{61-63}$

The strengths of our study include the use of prospectively collected data from a large multicentre cohort, defined by gestational age (rather than birthweight), ${ }^{64}$ and the use of follow-up data collected by examiners who were trained in the standardised administration of the BSID-II. Examiners were masked to infants' medical histories, including the infant's corrected gestational age at the follow-up visit.

A potential limitation of our study is the lack of a consistent method for obtaining MAP. Some MAP measurements were obtained by intra-arterial catheters, others by oscillometry. The latter method overestimates blood pressure. ${ }^{656}$ The direction of the resulting bias would depend on whether an association exists between the method by which infants' blood pressures were measured and their risks of developmental delay. Other limitations include the intermittent collection of MAP data, and the possibility that we missed the lowest MAP during the first $24 \mathrm{~h}$. To the extent that early volume expansion ameliorates the adverse effects of hypotension, inferences 
Table 3 Maternal characteristics, indicators of hypotension and developmental delay (row per cents)

\begin{tabular}{|c|c|c|c|c|c|c|c|}
\hline \multirow[b]{2}{*}{ Maternal characteristics } & & \multirow{2}{*}{$\begin{array}{l}\text { Lowest 1/4ile } \\
\text { MAP* }\end{array}$} & \multirow[b]{2}{*}{ Vasopressor $^{\dagger}$} & \multirow[b]{2}{*}{ Labile MAP ${ }^{\ddagger}$} & \multicolumn{2}{|c|}{ BSID $<70$} & \multirow[b]{2}{*}{$\mathbf{N}$} \\
\hline & & & & & MDI & PDI & \\
\hline \multirow[t]{5}{*}{ Years of education } & $<12$ & 27 & 25 & 23 & 43 & 33 & 147 \\
\hline & 12 (High school) & 23 & 23 & 24 & 32 & 38 & 244 \\
\hline & $>12$ to $<16$ & 20 & 22 & 28 & 26 & 30 & 214 \\
\hline & College grad & 19 & 27 & 24 & 16 & 28 & 172 \\
\hline & $>16$ & 24 & 34 & 21 & 15 & 26 & 137 \\
\hline \multirow[t]{2}{*}{ Married } & Yes & 20 & 26 & 21 & 22 & 30 & 560 \\
\hline & No & 25 & 26 & 27 & 33 & 35 & 385 \\
\hline \multirow[t]{2}{*}{ Self supported } & Yes & 21 & 28 & 21 & 25 & 33 & 623 \\
\hline & No & 25 & 21 & 30 & 31 & 29 & 302 \\
\hline \multirow[t]{2}{*}{ Public insurance } & Yes & 26 & 24 & 29 & 36 & 36 & 352 \\
\hline & No & 20 & 26 & 21 & 21 & 29 & 574 \\
\hline \multirow[t]{2}{*}{ Primigravida } & Yes & 24 & 29 & 22 & 20 & 32 & 371 \\
\hline & No & 21 & 24 & 26 & 32 & 32 & 549 \\
\hline \multirow[t]{2}{*}{ Any conception assistance } & Yes & 18 & 33 & 17 & 18 & 34 & 201 \\
\hline & No & 23 & 24 & 26 & 29 & 31 & 718 \\
\hline \multirow[t]{2}{*}{ Pre-pregnancy } & $<18.5$ & 26 & 27 & 26 & 23 & 33 & 66 \\
\hline & $18.5-25$ & 21 & 26 & 23 & 23 & 29 & 456 \\
\hline \multirow[t]{2}{*}{ BMI } & $25.1-30$ & 23 & 26 & 27 & 23 & 28 & 188 \\
\hline & $\geq 30$ & 24 & 24 & 23 & 38 & 41 & 197 \\
\hline \multirow[t]{2}{*}{ Vaginitis } & Yes & 21 & 21 & 30 & 37 & 38 & 126 \\
\hline & No & 22 & 26 & 23 & 25 & 30 & 792 \\
\hline \multirow[t]{2}{*}{ Aspirin } & Yes & 21 & 31 & 21 & 35 & 37 & 52 \\
\hline & No & 22 & 25 & 24 & 26 & 31 & 863 \\
\hline \multirow[t]{6}{*}{ Pregnancy complication } & Preterm labour & 21 & 27 & 22 & 25 & 33 & 427 \\
\hline & pPROM & 23 & 25 & 25 & 27 & 32 & 206 \\
\hline & Pre-eclampsia & 20 & 20 & 26 & 32 & 33 & 123 \\
\hline & Abruption & 24 & 25 & 30 & 18 & 23 & 104 \\
\hline & Cerv insufficiency & 25 & 36 & 21 & 34 & 39 & 53 \\
\hline & Fetal indication & 25 & 28 & 25 & 44 & 34 & 32 \\
\hline
\end{tabular}

*Lowest 1/4ile MAP: lowest mean arterial pressure recorded in the first $24 \mathrm{~h}$, in the lowest quartile for gestational age.

'Vasopressor: treatment for hypotension in the first $24 \mathrm{~h}$, using any vasopressor (dopamine, dobutamine, epinephrine).

${ }^{\ddagger}$ Labile MAP: labile blood pressure, defined as the upper quartile of the difference in the lowest and highest mean arterial pressure.

BMI, body mass index; BSID, Bayley Scales of Infant Development; Cerv insufficiency, cervical insufficiency;

MDI, Mental Developmental Index; PDI, Psychomotor Developmental Index; pPROM, preterm premature rupture of membranes.

from our study are most pertinent to populations in which volume expansion is used frequently, as $75 \%$ of ELGANs in this study received volume expansion in the first $24 \mathrm{~h}$. If volume expansion is not beneficial, our inferences might apply more broadly. Finally, we acknowledge that the agreement between early developmental assessments (20-24 months) and schoolage outcomes (5-8 years) is not strong. ${ }^{67}$

We did not report on the presence or absence of acidosis for two reasons. First, the available data did not permit a temporal correlation between recorded blood pressure and blood gas measurements. Second, hypotension is only one of a number of events that contribute to acidosis in the early postnatal period. These factors include, but are not limited to, uteroplacental insufficiency, abruptio-placenta, maternal medications and chorioamnionitis. Consequently, acidosis reflects much more than poor systemic perfusion in the early postnatal period, and cannot, in isolation, be viewed as a surrogate for poor perfusion. Therefore, we chose to address only the contribution of early postnatal hypotension to developmental outcomes.

Despite these limitations, our study has implications for researchers interested in preventing developmental delay in extremely preterm infants. Specifically, our findings do not support the concept that early postnatal hypotension is an important risk factor for such delays, or the corollary that vasopressor therapy can prevent such delays.

The implications for clinicians are important as well, as ELGANs are frequently given treatments to increase blood pressure under the assumption that these treatments decrease the risk of brain injury. This assumption is not supported by observational studies, ${ }^{22} 68$ and there is a paucity of support for therapies widely used to treat hypotension. ${ }^{57} 69$ Treatment for hypotension has been associated with abnormal development, 227071 hearing loss ${ }^{22} 71$ and severe brain ultrasound abnormalities in low birthweight infants. ${ }^{9} 227072-75$ Thus, while it is possible the decision to treat reflects the physician's perception that the infant is vulnerable, it is also possible that these therapies are harmful.

In conclusion, we investigated the association between hypotension during the first day following birth and developmental delay, in a large cohort of extremely preterm newborns. We tested this association using three operational definitions. The first relied upon the distribution of MAPs and defined hypotension as the lowest MAP during this day in the lowest quartile. The second defined hypotension based on the lability of MAP during the first day. The third was based on 
Table 4 Frequencies of indicators of hypotension and developmental delay (row per cents)

\begin{tabular}{|c|c|c|c|c|c|c|c|}
\hline \multirow{2}{*}{\multicolumn{2}{|c|}{ Exposures and BSID outcomes }} & \multirow[b]{2}{*}{ Lowest $1 / 4$ ile MAP* } & \multirow[b]{2}{*}{ Vasopressor $^{\dagger}$} & \multirow[b]{2}{*}{ Labile MAP } & \multicolumn{2}{|c|}{ BSID $<70$} & \multirow[b]{2}{*}{$\mathbf{N}$} \\
\hline & & & & & $\overline{M D I}$ & PDI & \\
\hline \multirow[t]{2}{*}{ Lowest 1/4ile MAP* } & Yes & & 45 & 42 & 30 & 34 & 206 \\
\hline & No & & 20 & 19 & 25 & 31 & 739 \\
\hline \multirow[t]{2}{*}{ Vasopressor $^{\dagger}$} & Yes & 38 & & 30 & 31 & 35 & 244 \\
\hline & No & 16 & & 22 & 25 & 31 & 701 \\
\hline \multirow[t]{2}{*}{ Labile MAP ${ }^{\ddagger}$} & Yes & 39 & 32 & & 28 & 30 & 225 \\
\hline & No & 17 & 24 & & 26 & 32 & 720 \\
\hline \multirow[t]{2}{*}{ BSID MDI $<70$} & Yes & 25 & 30 & 26 & & 70 & 250 \\
\hline & No & 21 & 24 & 23 & & 20 & 695 \\
\hline \multirow[t]{2}{*}{ BSID PDI $<70$} & Yes & 24 & 28 & 22 & 58 & & 300 \\
\hline & No & 21 & 25 & 25 & 12 & & 645 \\
\hline \multicolumn{2}{|c|}{ Maximum number of infants } & 206 & 244 & 225 & 250 & 300 & 945 \\
\hline \multicolumn{2}{|l|}{ Row \% } & 22 & 26 & 24 & 26 & 32 & \\
\hline
\end{tabular}

*Lowest 1/4ile MAP: lowest mean arterial pressure recorded in the first $24 \mathrm{~h}$, in the lowest quartile for gestational age.

${ }^{\dagger}$ Vasopressor: treatment for hypotension in the first $24 \mathrm{~h}$, using any vasopressor (dopamine, dobutamine, epinephrine).

‡Labile MAP: labile blood pressure, defined as the upper quartile of the difference in the lowest and highest mean arterial pressure.

BSID, Bayley Scales of Infant Development; MDI, Mental Developmental Index; PDI, Psychomotor Developmental Index.

clinicians' decision to treat with a vasopressor. In a cohort of preterm infants, a majority of whom were treated with volume expanders, we found little evidence for an association between three early postnatal hypotension indicators and developmental delay at 24-month follow-up.

\section{Participating institutions (site principal investigators and} neuro-developmental examiners):

Baystate Medical Center, Springfield, MA (Bhavesh Shah, Solveg Pflueger, Herbert Gilmore, Susan McQuiston).

Beth Israel Deaconess Medical Center, Boston, MA (Camilia R Martin).

Brigham \& Women's Hospital, Boston, MA (Linda J Van Marter).

Children's Hospital Boston, Boston, MA (Alan Leviton, Samantha Butler, Haim

Bassan, Adré Duplessis, Cecil Hahn, Omar Khwaha, AK Morgan, Janet S Soul).

DeVos Children's Hospital, Grand Rapids, MI (Mariel Portenga, Barbara Doss,

Wendy Burdo-Hartman, Lynn Fagerman, Kim Lohr, Steve Pastynrnak, Dinah

Sutton).

Floating Hospital for Children at Tufts Medical Center, Boston, MA (Cynthia Cole/ John Fiascone, Ina Bhan, Paige T Church, Cecelia Keller, Karen Miller).

Massachusetts General Hospital, Boston, MA (Robert Insoft, Drucilla Roberts,

Kalpathy Krishnamoorthy).

Michigan State University, Lansing, MI (Nigel Paneth).

North Carolina Children's Hospital, Chapel Hill, NC (Carl Bose, Chad Livasy, Lisa Bostic, Janice Wereszczak, Diane Marshall, Kristi Milowic, Carol Hubbard). Sparrow Hospital, Lansing, MI (Padmani Karna, Gabriel Chamyan, Victoria J Caine, Padmani Karna, Nicholas Olomu, Joan Price).

University of Chicago Hospital, Chicago, IL (Michael D Schreiber, Aliya Husain, Leslie Caldarelli, Sunila E O'Conno, Michael Msall, Susan Plesha-Troyke). University Health Systems of Eastern Carolina, Greenville, NC (Stephen Engelke, Sharon Buckwald, Rebecca Helms, Kathyrn Kerkering, Scott S MacGilvray, Peter Resnik).

U Mass Memorial Health Center, Worcester, MA (Francis Bednarek, Karen Strehloh, Robin Adair, Richard Bream, Alice Miller, Albert Scheiner, Christy Stine). Wake Forest University Baptist Medical Center and Forsyth Medical Center, Winston-Salem, NC (T. Michael O'Shea, Deborah Allred, Don Goldstein, Gail Hounshell, Robert Dillard, Cherrie Heller, Debbie Hiatt, Lisa Washburn). William Beaumont Hospital, Royal Oak, MI (Daniel Batton, Chung-ho Chang, Karen Brooklier, Melisa Oca).

Yale University School of Medicine, New Haven, CT (Richard Ehrenkranz, Vinita Parkas, Nancy Close, Elaine Romano, Joanne Williams).

Acknowledgements The authors gratefully acknowledge the contributions of our subjects and their families, as well as those of our colleagues.

Funding This study was supported by a cooperative agreement with the National Institute of Neurological Disorders and Stroke (5U01NS040069-05) and a programme project grant form the National Institute of Child Health and Human Development (NIH-P30-HD-18655).

\section{Competing interests None.}

Ethics approval The study protocol was approved by the institutional review boards of the 14 participating institutions. An external Operations Advisory Group, appointed by the principal investigator and approved by the sponsor, was charged with assuring patient safety.

Provenance and peer review Not commissioned; externally peer reviewed.

\section{REFERENCES}

1. Greisen G. Autoregulation of cerebral blood flow in newborn babies. Early Hum Dev 2005;81:423-8.

2. Soul JS, Hammer PE, Tsuji M, et al. Fluctuating pressure-passivity is common in the cerebral circulation of sick premature infants. Pediatr Res 2007;61:467-73.

3. Weindling AM, Wilkinson AR, Cook J, et al. Perinatal events which precede periventricular haemorrhage and leukomalacia in the newborn. Br J Obstet Gynaecol 1985;92:1218-23.

4. Miall-Allen VM, de Vries LS, Whitelaw AG. Mean arterial blood pressure and neonatal cerebral lesions. Arch Dis Child 1987;62:1068-9.

5. Watkins AM, West CR, Cooke RW. Blood pressure and cerebral haemorrhage and ischaemia in very low birthweight infants. Early Hum Dev 1989;19:103-10.

6. Bada HS, Korones SB, Perry EH, et al. Mean arterial blood pressure changes in premature infants and those at risk for intraventricular hemorrhage. J Pediatr 1990;117:607-14.

7. Low JA, Froese AB, Smith JT, et al. Hypotension and hypoxemia in the preterm newborn during the four days following delivery identify infants at risk of echosonographically demonstrable cerebral lesions. Clin Invest Med 1992;15:60-5.

8. Low JA, Froese AB, Galbraith RS, et al. The association between preterm newborn hypotension and hypoxemia and outcome during the first year. Acta Paediatr 1993:82:433-7.

9. O'Shea TM, Kothadia JM, Roberts DD, et al. Perinatal events and the risk of intraparenchymal echodensity in very-low-birthweight neonates. Paediatr Perinat Epidemiol 1998;12:408-21.

10. Trounce JQ, Shaw DE, Levene MI, et al. Clinical risk factors and periventricular leucomalacia. Arch Dis Child 1988;63:17-22.

11. de Vries LS, Regev R, Dubowitz LM, et al. Perinatal risk factors for the development of extensive cystic leukomalacia. Am J Dis Child 1988;142:732-5.

12. Bejar RF, Vaucher YE, Benirschke K, et al. Postnatal white matter necrosis in preterm infants. J Perinatol 1992;12:3-8.

13. D'Souza SW, Janakova H, Minors D, et al. Blood pressure, heart rate, and skin temperature in preterm infants: associations with periventricular haemorrhage. Arch Dis Child Fetal Neonatal Ed 1995;72:F162-7.

14. Perlman JM, Risser R, Broyles RS. Bilateral cystic periventricular leukomalacia in the premature infant: associated risk factors. Pediatrics 1996;97:822-7.

15. Wiswell TE, Graziani LJ, Kornhauser MS, et al. Effects of hypocarbia on the development of cystic periventricular leukomalacia in premature infants treated with high-frequency jet ventilation. Pediatrics 1996;98:918-24.

16. Baud $\mathbf{0}$, Ville $Y$, Zupan V, et al. Are neonatal brain lesions due to intrauterine infection related to mode of delivery? Br J Obstet Gynaecol 1998;105:121-4.

17. Cunningham S, Symon AG, Elton RA, et al. Intra-arterial blood pressure reference ranges, death and morbidity in very low birthweight infants during the first seven days of life. Early Hum Dev 1999;56:151-65.

18. Dammann 0, Allred EN, Kuban KC, et al. Systemic hypotension and white-matter damage in preterm infants. Dev Med Child Neurol 2002;44:82-90. 
19. Limperopoulos C, Bassan H, Kalish LA, et al. Current definitions of hypotension do not predict abnormal cranial ultrasound findings in preterm infants. Pediatrics 2007;120:966-77.

20. Goldstein RF, Thompson RJ Jr, Oehler JM, et al. Influence of acidosis, hypoxemia, and hypotension on neurodevelopmental outcome in very low birth weight infants. Pediatrics 1995;95:238-43

21. Batton B, Zhu X, Fanaroff J, et al. Blood pressure, anti-hypotensive therapy, and neurodevelopment in extremely preterm infants. J Pediatr 2009;154:351-7, 357.e1.

22. Kuint J, Barak M, Morag I, et al. Early treated hypotension and outcome in very low birth weight infants. Neonatology 2009;95:311-16.

23. McElrath TF, Hecht JL, Dammann 0, et al. Pregnancy disorders that lead to delivery before the 28th week of gestation: an epidemiologic approach to classification. Am J Epidemio/ 2008;168:980-9.

24. Yudkin PL, Aboualfa M, Eyre JA, et al. New birthweight and head circumference centiles for gestational ages 24 to 42 weeks. Early Hum Dev 1987;15:45-52.

25. Laughon M, Bose C, Allred E, et al. Factors associated with treatment for hypotension in extremely low gestational age newborns during the first postnatal week. Pediatrics 2007;119:273-80.

26. Bayley N. Bayley Scales of Infant Development-II. San Antonio, TX: Psychological Corporation 1993.

27. Sparrow SS, Cicchetti DV. Diagnostic uses of the Vineland Adaptive Behavior Scales. J Pediatr Psychol 1985;10:215-25.

28. Dales LG, Ury HK. An improper use of statistical significance testing in studying covariables. Int J Epidemiol 1978;7:373-5.

29. Begg MD, Parides MK. Separation of individual-level and cluster-level covariate effects in regression analysis of correlated data. Stat Med 2003;22:2591-602.

30. Richardson DK, Corcoran JD, Escobar GJ, et al. SNAP-II and SNAPPE-II: Simplified newborn illness severity and mortality risk scores. J Pediatr 2001;138:92-100.

31. Munro MJ, Walker AM, Barfield CP. Hypotensive extremely low birth weight infants have reduced cerebral blood flow. Pediatrics 2004;114:1591-6.

32. Pellicer A, Valverde E, Elorza MD, et al. Cardiovascular support for low birth weight infants and cerebral hemodynamics: a randomized, blinded, clinical trial. Pediatrics 2005;115:1501-12.

33. Boylan GB, Young K, Panerai RB, et al. Dynamic cerebral autoregulation in sick newborn infants. Pediatr Res 2000;48:12-17.

34. Evans N, Kluckow M, Simmons M, et al. Which to measure, systemic or organ blood flow? Middle cerebral artery and superior vena cava flow in very preterm infants. Arch Dis Child Fetal Neonatal Ed 2002;87:F181-4.

35. Osborn D, Evans N, Kluckow M. Randomized trial of dobutamine versus dopamine in preterm infants with low systemic blood flow. J Pediatr 2002;140:183-91.

36. Groves AM, Kuschel CA, Knight DB, et al. Relationship between blood pressure and blood flow in newborn preterm infants. Arch Dis Child Fetal Neonatal Ed 2008;93:F29-32.

37. Pladys $\mathbf{P}$, Wodey E, Beuchée A, et al. Left ventricle output and mean arterial blood pressure in preterm infants during the 1st day of life. Eur J Pediatr 1999;158:817-24.

38. Miletin J, Pichova K, Dempsey EM. Bedside detection of low systemic flow in the very low birth weight infant on day 1 of life. Eur J Pediatr 2008;168:809-13.

39. Tsuji M, Saul JP, du Plessis A, et al. Cerebral intravascular oxygenation correlates with mean arterial pressure in critically ill premature infants. Pediatrics 2000:106:625-32.

40. Wong FY, Leung TS, Austin T, et al. Impaired autoregulation in preterm infants identified by using spatially resolved spectroscopy. Pediatrics 2008;121:e604-11.

41. Wardle SP, Yoxall CW, Weindling AM. Determinants of cerebral fractional oxygen extraction using near infrared spectroscopy in preterm neonates. J Cereb Blood Flow Metab 2000;20:272-9.

42. Victor S, Appleton RE, Beirne M, et al. The relationship between cardiac output, cerebral electrical activity, cerebral fractional oxygen extraction and peripheral blood flow in premature newborn infants. Pediatr Res 2006;60:456-60.

43. Kissack CM, Garr R, Wardle SP, et al. Cerebral fractional oxygen extraction in very low birth weight infants is high when there is low left ventricular output and hypocarbia but is unaffected by hypotension. Pediatr Res 2004;55:400-5.

44. Tyszczuk L, Meek J, Elwell C, et al. Cerebral blood flow is independent of mean arterial blood pressure in preterm infants undergoing intensive care. Pediatrics 1998:102:337-41.

45. Lightburn MH, Gauss CH, Williams DK, et al. Cerebral blood flow velocities in extremely low birth weight infants with hypotension and infants with normal blood pressure. J Pediatr 2009:154:824-8.

46. Ment LR, Duncan CC, Ehrenkranz RA, et al. Intraventricular hemorrhage in the preterm neonate: timing and cerebral blood flow changes. J Pediatr 1984; 104:419-25

47. Meek JH, Tyszczuk L, Elwell CE, et al. Low cerebral blood flow is a risk factor for severe intraventricular haemorrhage. Arch Dis Child Fetal Neonatal Ed 1999;81:F15-18.
48. Kluckow M, Evans N. Low superior vena cava flow and intraventricular haemorrhage in preterm infants. Arch Dis Child Fetal Neonatal Ed 2000;82:F188-94.

49. Osborn DA, Evans N, Kluckow M. Hemodynamic and antecedent risk factors of early and late periventricular/intraventricular hemorrhage in premature infants. Pediatrics 2003;112:33-9

50. Kissack CM, Garr R, Wardle SP, et al. Postnatal changes in cerebral oxygen extraction in the preterm infant are associated with intraventricular hemorrhage and hemorrhagic parenchymal infarction but not periventricular leukomalacia. Pediatr Res 2004;56:111-16.

51. Miletin J, Dempsey EM. Low superior vena cava flow on day 1 and adverse outcome in the very low birthweight infant. Arch Dis Child Fetal Neonatal Ed 2008;93:F368-71.

52. Leviton A, Pagano M, Kuban KC, et al. The epidemiology of germinal matrix hemorrhage during the first half-day of life. Dev Med Child Neurol 1991;33:138-45.

53. Collins MP, Lorenz JM, Jetton JR, et al. Hypocapnia and other ventilationrelated risk factors for cerebral palsy in low birth weight infants. Pediatr Res 2001:50:712-19.

54. Pryds 0, Greisen G, Lou H, et al. Heterogeneity of cerebral vasoreactivity in preterm infants supported by mechanical ventilation. J Pediatr 1989;115:638-45

55. Kaiser JR, Gauss CH, Williams DK. Surfactant administration acutely affects cerebral and systemic hemodynamics and gas exchange in very-low-birth-weight infants. J Pediatr 2004;144:809-14.

56. Kaiser JR, Gauss CH, Williams DK. The effects of hypercapnia on cerebral autoregulation in ventilated very low birth weight infants. Pediatr Res 2005:58:931-5.

57. Pellicer A, Bravo MC, Madero R, et al. Early systemic hypotension and vasopressor support in low birth weight infants: impact on neurodevelopment. Pediatrics 2009;123:1369-76.

58. Freemantle N, Calvert M, Wood J, et al. Composite outcomes in randomized trials: greater precision but with greater uncertainty? JAMA 2003;289:2554-9.

59. Mehio-Sibai A, Feinleib M, Sibai TA, et al. A positive or a negative confounding variable? A simple teaching aid for clinicians and students. Ann Epidemiol 2005;15:421-3.

60. Wood NS, Costeloe K, Gibson AT, et al. The EPICure study: associations and antecedents of neurological and developmental disability at 30 months of age following extremely preterm birth. Arch Dis Child Fetal Neonatal Ed 2005;90:F134-40.

61. Psaty BM, Koepsell TD, Lin D, et al. Assessment and control for confounding by indication in observational studies. J Am Geriatr Soc 1999:47:749-54.

62. Signorello LB, McLaughlin JK, Lipworth L, et al. Confounding by indication in epidemiologic studies of commonly used analgesics. Am J Ther 2002;9:199-205.

63. Walker AM. Confounding by indication. Epidemiology 1996;7:335-6.

64. Arnold CC, Kramer MS, Hobbs CA, et al. Very low birth weight: a problematic cohort for epidemiologic studies of very small or immature neonates. Am J Epidemiol 1991;134:604-13.

65. 0'Shea J, Dempsey EM. A comparison of blood pressure measurements in newborns. Am J Perinatol 2009:26:113-16.

66. Troy $\mathbf{R}$, Doron $\mathrm{M}$, Laughon $\mathrm{M}$, et al. Comparison of noninvasive and central arterial blood pressure measurements in ELBW infants. J Perinatol 2009;29:744-9.

67. Hack M, Taylor HG, Drotar D, et al. Poor predictive validity of the Bayley Scales of Infant Development for cognitive function of extremely low birth weight children at school age. Pediatrics 2005;116:333-41.

68. Dempsey EM, Al Hazzani F, Barrington KJ. Permissive hypotension in the extremely low birthweight infant with signs of good perfusion. Arch Dis Child Fetal Neonatal Ed 2009:94:F241-4

69. Dempsey EM, Barrington KJ. Treating hypotension in the preterm infant: when and with what: a critical and systematic review. J Perinatol 2007:27:469-78.

70. Greenough A, Cheeseman P, Kavvadia V, et al. Colloid infusion in the perinatal period and abnormal neurodevelopmental outcome in very low birth weight infants. Eur J Pediatr 2002:161:319-23.

71. Fanaroff JM, Wilson-Costello DE, Newman NS, et al. Treated hypotension is associated with neonatal morbidity and hearing loss in extremely low birth weight infants. Pediatrics 2006;117:1131-5.

72. Goldberg RN, Chung D, Goldman SL, et al. The association of rapid volume expansion and intraventricular hemorrhage in the preterm infant. J Pediatr 1980:96:1060-3

73. Salafia CM, Minior VK, Rosenkrantz TS, et al. Maternal, placental, and neonatal associations with early germinal matrix/intraventricular hemorrhage in infants born before 32 weeks' gestation. Am J Perinatol 1995;12:429-36.

74. Synnes AR, Chien LY, Peliowski A, et al. Variations in intraventricular hemorrhage incidence rates among Canadian neonatal intensive care units. J Pediatr 2001; 138:525-31.

75. Batton B, Batton D, Riggs T. Blood pressure during the first 7 days in premature infants born at postmenstrual age 23 to 25 weeks. Am J Perinatol 2007:24:107-15. 